\title{
EFEKTIVITAS RASA INGIN TAHU (KURIOSITAS) ANAK USIA DINI MELALUI EDUTAINMENT DENGAN METODE SAINS SEDERHANA
}

\author{
Siti Rohmah ${ }^{1}$, Siti Hana ${ }^{2}$, Heni Nafiqoh ${ }^{3}$ \\ ${ }^{1}$ Institut Keguruan Ilmu Pendidikan (IKIP) Siliwangi, Jalan Terusan Jenderal Sudirman Cimahi \\ ${ }^{2}$ Institut Keguruan Ilmu Pendidikan (IKIP) Siliwangi, Jalan Terusan Jenderal Sudirman Cimahi \\ ${ }^{3}$ Institut Keguruan Ilmu Pendidikan (IKIP) Siliwangi, Jalan Terusan Jenderal Sudirman Cimahi \\ sitirohmah18282@,gmail.com ${ }^{1}$, sitihana79@yahoo.con ${ }^{3}$, heninafiqoh@ikipsiliwangi.co.id ${ }^{3}$.
}

\begin{abstract}
This study examnes the effctiveness of early childhood curiosity through edutainment using simple scientific methods. The goal to be achieved by researchers in this study is to find out and analyze how effective the use of simple scientific methods in increasing early childhood curiosity. This research was caried out using a quasi-experimental method with the sample of 15 students from group A that divided into two groups. The data collection process is carried out by interviewing the relevant teacher and observing the children. The of use simple scientific methods through edutainment for the effectiveness of early childhood curiosity is done as much as 8 (eight) meetings. The results obtained through observation and calculation of the pretest and posttest scores with the average value of the two groups showed that the experimental group had an influence on the effctiveness of early childhood curiosity through edutainment with simple science methods with a percentage of $84.8 \%$ Besides that, the process learning that using ordinary methods or lecture method in the control class get a percentage of $25.9 \%$.
\end{abstract}

Keywords : Curiosity, Edutainment, Scientific Methods.

\begin{abstract}
ABSTRAK
Penelitian ini mengkaji tentang keefektivitasan kuriositas anak didik dibawah usia 8 tahun melalui edutainment dengan menggunakan metode sains sederhana. Tujuan yang ingin dicapai oleh peneliti dalam penelitian ini adalah untuk mengetahui dan menganalisis seberapa efektifnya penggunaan metode sains sederhana dalam meningkatkan kuriositas anak usia dini. Penelitian ini dilaksanakan dengan menggunakan metode quasi eksperimen dengan sumber datanya adalah anak - anak kelompok A yang berjumlah 14 orang, dan dibagi menjadi dua kelompok. Pengumpulan data dilakukan dengan cara mewawancarai guru yang terkait serta mengobservasi anak - anak. Penggunaan metode sains sederhana melalui edutainment untuk keefektivitasan rasa ingin tahu anak usia dini dilakukan sebanyak 8 (delapan) kali pertemuan. Hasil yang diperoleh melalui observasi serta perhitungan nilai pretest dan posttest dengan nilai rata-rata kedua grup menunjukan bahwa grup eksperimen memiliki pengaruh terhadap keefektivitasan kuriositas anak usia dini melalui edutainment dengan metode sains sederhana dengan persentase $84.8 \%$ dibandingkan dengan pembelajaran yang menggunakan metode biasa atau metode ceramah pada kelas kontrol dengan hasil persentase $25,9 \%$.
\end{abstract}

Kata kunci: Rasa Ingin Tahu, Edutainment, Metode Sains. 


\section{PENDAHULUAN}

Perkembagan teknologi dan pemahaman manusia masa sekarang demikian cepat berkembang, menjadikan persaingan semakin tidak terarah dan tajam. Sehingga kita harus mempersiapkan genrasi yang berkarakter dan tangguh agar bisa bersaing dengan sehat. Pendidikan yang harus diberikan saat ini harus membekali anak didik dengan pemahaman ilmu dan keterampilan semata, tetapi yang sangat penting adalah pengembangan karakter yang kuat dan kegigihan guru dalam memberikan pengarahan.

Metode yang paling tepat dalam memupuk serta mengembangkan keingin tahuan anak dalm bidang sains diantaranya adalah dengan "permainan sains", yakni pembelajaran sains yang mengasyikan dan familiar untuk dilaksanakan bagi anak, agar anak secara aktif mencari penjelasan tentang segala sesuatu yang terjadi disekitarnya. Ini merupakan suatu pencarian atau penjelajahan di bidang sains, dimana anak mampu memahami dunia nya melalui pengamatan, penyelidikan, dan percobaan sederhana.

Menurut webster dictionary new collegiate (2013 :7) sains ialah pengetahuan yang didapat dengan pembuktian mencangkup hukum hukum alam yang terjadi serta dibuktikan kebenarannya dengan metode ilmah atau dijelaskan secara detail. Dalam hal ini, sains merujuk kesebuah sisitem untuk mendapatkan pemahaman yang menggunakan pengamatan dan eksperimen untuk menggambarkan dan menjelaskan kejadian yang terjadi dialam sekitar. Berdasarkan definisi diatas maka sains yang di kehendaki dalam penelitian ini adalah sains yang lebih menekankan kepada metode atau strategi yang dipakai dalam proses pembelajaran, sehingga dapat menjawab kuriositas anak didik.

Setiap peserta didik/ anak memiliki hak yang sama dalam pendidikan baik anak didik yang terletak dikampung maupun yang berada dikota, tapi kenyataan yang berada saat ini berbanding terbalik, pendidikan yang berada di kampung tertinggal jauh oleh pendidikan dikota baik dalam hal pengajaran maupun dalam hal medianya.

Pembelajaran di anak didik usia 4 - 5 tahun di TK Harapan Makiyyah tidak tersiah dari berbagai persoalan yang terjadi, berdasarkan pengalaman peneliti sebagai guru yang mengajar tersebut, salah satu yang menjadi masalah adalah pengenalan warna belum dapat mencapai hasil yang setinggi - tingginya sesuai dengan harapan guru maupun tujuan dari pelaksanaan pembelajaran. Banyak faktor yang menjadi penyebab masalah pengembangan kemampuan anak mengenal warna, salah satunya karena pendidik tidak pernh mengenalkan warna melalui metode eksperimen.

\section{METODOLOGI}

Metode penelitian yang digunakan dalam penelitian menggunakan metode eksperimen semu. Menurut Yusuf (2016:78) quasi eksperimen merupakan salah satu tipe penyelidikan yang tidak melakukan randomisasi (ramdomnes) atau secara acak dalam penetapan subjek grup penelitian, tetapi memiliki hasil yang cukup berarti, baik ditinjau dari legalitas internal maupun eksternal.

Sempel pada penelitian ini berjumlah 14 anak yang dibagi menjadi 


\section{JURNAL GERIA}

ISSN : 2614-6347 (Print) 2714-4107 (Online)

Vol.2 | No.5 | September 2019

dua grup, yaitu grup eksperimen 7 orang dan grup kontrol 7 orang.

Pengambilan data menggunakan pedoman observasi dan wawancara, yang terletak pada pernyataan kisi - kisi yang disusun berdasarkan indikator pencapaian perkembangan anak, untuk memperkirakan tingkat pengetahuan yang harus dicapai oleh anak. Penghitungan yang digunakan menggunakan analisis statistik deskriptif. Analisis ini menggunakan aplikasi SPSS versi 18.

\section{HASIL DAN PEMBAHASAN Hasil}

Pengumpulan data diperoleh dari data hasil tes lisan menggunakan pedoman observasi. Tes lisan yang diberikan berupa pretest dan posttest. Pretest diberikan sebelum dilaksanakannya pemberian treatment pada grup eksperimen. Sedangkan pelaksanaan posttest dilaksanakan setelah pemberian treatment pada grup eksperimen dan grup kontrol.

Sebelum menganalisis data lebih lanjut, peneliti melakukan uji normalitas dan uji homogenitas terlebih dahulu, untuk mengetahui responden tersebut tergolong kedalam homogen dan normal. Kemudian melakukan uji analisis selanjutnya dengan menggunakan uji hipotesis seperti uji pembeda dan uji N-Gain. Hasilnya disajikan dalam bentuk tabel untuk memudahkan pemahaman terhadap hasil penelitian tersebut.

Peneliti menggunakan uji normalitas dengan rumus Saphiro Wilk, karena responde yang peneliti ambil dibawah 50 orang responden. Berdasarkan rumus yang akan di gunakan di aplikasi SPSS 18 maka hasil yang didapat sebagai berikut:

\begin{tabular}{|ll|c|c|c|}
\hline \multirow{2}{*}{ kelompok } & \multicolumn{3}{|c|}{ Shapiro-Wilk } \\
\cline { 3 - 5 } & $\begin{array}{c}\text { Statisti } \\
\mathrm{c}\end{array}$ & $\mathrm{df}$ & Sig. \\
\hline $\begin{array}{l}\text { hasil } \\
\text { belajar }\end{array}$ & $\begin{array}{l}\text { kelompok } \\
\text { eksperimen } \\
\text { kelompok } \\
\text { kontrol }\end{array}$ &, 831 & 7 &, 082 \\
& & 756 &, 139 \\
\hline
\end{tabular}

Berdasarkan tabel yang terdapat diatas dapat dilihat bahwa signifikansi nilai grup eksperimen sebesar 0,082 sedangkan nilai signifikansi grup kontrol sebesar 0,139 . nilai signifikansi keduanya $>0,05$, yang berarti Ho diterima dan Ha ditolak. Yang berarti grup eksperimen dan grup kontrol berasal dari populasi yang terdistribusi normal.

Setelah data terbukti normal maka peneliti dapat melanjutkan penelitian ketahap pengujian selanjutnya yaitu pengujian homogenitas untuk memafhumi apakah responden tersebut memiliki kemampuan yang sejajar atau tidak, penghitungan uji homogenitas pun memakai aplikasi SPSS 18 dan hasil yang didapat sebagai berikut:

\section{Tabel 1}

Test of Homogeneity of Variances

\begin{tabular}{|r|r|r|c|}
\hline $\begin{array}{c}\text { Levene } \\
\text { Statistic }\end{array}$ & df1 & \multicolumn{1}{c|}{ df2 } & Sig. \\
\hline, 715 & 1 & 12 &, 414 \\
\hline
\end{tabular}

Dilihat dari tabel diatas yang menunjukan hasil uji homogenitas yang diperoleh yakni 0,414 perbandingan aturan penetapannya memperoleh nilai $0,414>0,05$, sehingga diperoleh kesimpulan bahwa data pretest grup eksperimen dan grup kontrol merupakan data yang sejenis atau homogen.

Setelah peneliti mengetahui bahwa hasil penghitungan normalitas dan homogenitas terhadap responden yang akan diteliti dikatakan normal dan homogen. Maka peneliti melanjutkan 


\section{JURNAL GERIA}

ISSN : 2614-6347 (Print) 2714-4107 (Online)

Vol.2 | No.5 | September 2019

pengujian terhadap hipotesis yang telah disusun sebelumnya tentang efektivitas kuriositas melalui edutainment dengan metode sains sederhana tersebut efektif atau tidak.

Untuk menganalisis hipotesis

Tabel 2

Paired Samples Statistics

\begin{tabular}{|ll|r|r|}
\hline & & Mean & N \\
\hline Pair 1 & Pre Test & 85,00 & 7 \\
& Post Test & 88,71 & 7 \\
\hline
\end{tabular}

tersebut peneliti menggunakan uji pembeda menggunakan aplikasi SPSS 18, dengan hasil perhitungan sebagai berikut untuk kelas eksperimen.

Tabel 3

Paired Samples Statistics

\begin{tabular}{|ll|r|r|}
\hline & & Mean & \multicolumn{1}{|c|}{ N } \\
\hline Pair 1 & Pre Test & 87,71 & 7 \\
& Post Test & 97,57 & 7 \\
\hline
\end{tabular}

Tabel 4

Paired Samples Correlations

\begin{tabular}{|ll|c|c|c|}
\hline & $\mathrm{N}$ & $\begin{array}{c}\text { Correlat } \\
\text { ion }\end{array}$ & Sig. \\
\hline Pair 1 & $\begin{array}{l}\text { Pre Test \& } \\
\text { Post Test }\end{array}$ & 7 &, 479 &, 277 \\
\hline
\end{tabular}

NILAI RATA RATA KELAS EKSPERIMEN

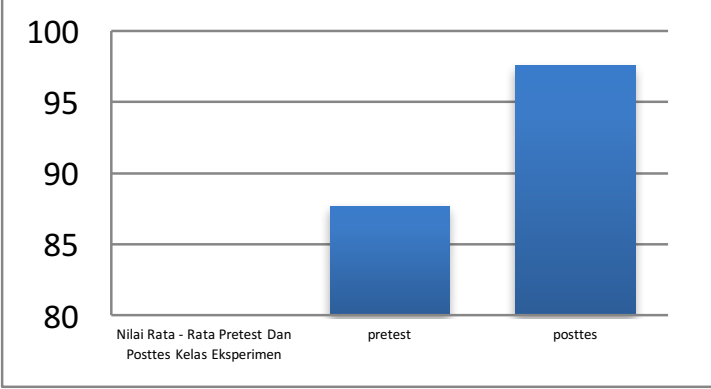

Grafik 1

Nilai Rata-rata Kelas Eksperimen

Sebelum pembelajaran sains sederhana, rata-rata efektivitas kuriositas dari 7 siswa adalah sebanyak 87,71, sementara setelah pembelajaran sains sederhana, rata-rata efektivitas kuriositas adalah sebesar 97,57. Sedangkan hubungan antara dua variabel adalah sebesar 0.479 dengan sig sebesar 0.277. Hal ini menunjukkan bahwa korelasi antara dua rata-rata efektivitas kuriositas sebelum dan setelah pembelajaran sains sederhana adalah signifikan.

Sedangkan hasil perhitungan uji pembeda untuk kelas kontrol sebagai berikut:

Tabel 5

Paired Samples Correlations

\begin{tabular}{|ll|r|r|r|}
\hline & $\mathrm{N}$ & $\begin{array}{c}\text { Correlati } \\
\text { on }\end{array}$ & Sig. \\
\hline Pair 1 & $\begin{array}{l}\text { Pre Test } \\
\text { \& Post } \\
\text { Test }\end{array}$ & 7 &, 844 &, 017 \\
\hline
\end{tabular}

NILAI RATA RATA KLAS KONTROL

Rata Pretest Dan Posttes posttes

Grafik 2

Nilai Rata-rata Kelas Eksperimen

Selanjutnya dilakukan pengujian NGain, pengujian N-Gain dilakukan agar mengetahui efektivitas penggunaan suatu metode tertentu dalam penelitian quasi eksperimen. Uji N-Gain score dilakukan dengan cara membilang perbedaan antara score pretest dan score posttest. Hasil penghitungan NGain untuk penelitian efektivitas kuriositas melalui edutainment dengan metode sains sederhana sebagai berikut: 


\section{JURNAL GERIA}

ISSN : 2614-6347 (Print) 2714-4107 (Online)

Vol.2 | No.5 | September 2019

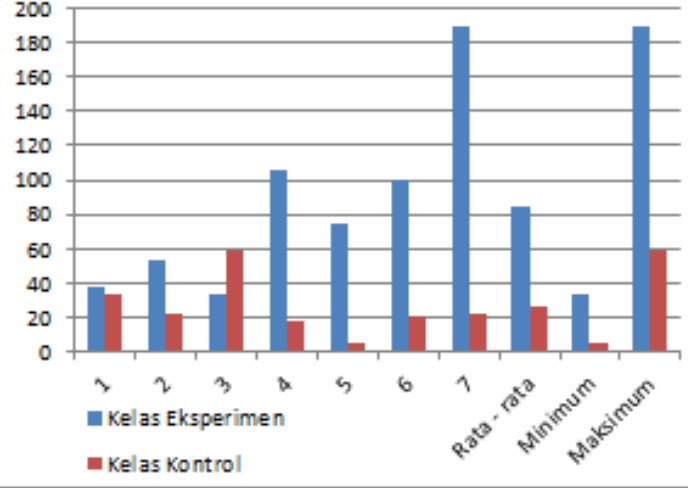

Dapat dilihat dari grafik nilai uji NGain di atas kelas eksperimen memiliki selisih yang signifikan dari kelas kontrol, terbukti dari score rata - rata NGain score untuk kelas eksperimen adalah sebesar 84,8448 atau $84,8 \%$ tercantum pada kategori efektif. Dengan nilai $\mathrm{N}$-Gain score minimal 33,3\% dan maksimal 188,8\%. Sementara untuk rata - rata N-Gain score untuk kelas kontrol adalah sebesar 25,8670 atau 25,9\% termasuk dalam kategori tidak efektif, dengan nilai $\mathrm{N}$-Gain score minimal $5,9 \%$ dan maksimal 58,33\%.

\section{KESIMPULAN}

Berdasarkan perhitungan uji paired sample t-tes data pretest dan posttes pada kedua kelompok eksperimen serta kelompok kontrol, maka peneliti menyimpulkan terdapat sebuah perbedaan yang cukup signifikan antara kelompok yang menerapkan metode sains sederhana dengan metode biasa atau ceramah.

Dengan perbandingan rata-rata kuriositas peserta didik yang menerapkan metode sains sederhana memiliki rata - rata nilai pretest 87,71 sedangkan kelas yang menerapkan metode biasa memiliki nilai 85,00. Rata-rata nilai posttest grup eksperimen adalah 97,57 sedangkan grup kontrol adalah 88,71. Berdasarkan hasil belajar tersebut, membuktikan bahwa grup eksperimen yang diberikan perlakuan berupa metode sains sederhana mendapati peningkatan hasil belajar lebih tinggi dibandingkan grup kontrol yang diberikan perlakuan berupa metode biasa.

Hal ini menunjukan bahwa keefektivitasan kuriositas anak didik dibawah usia 8 tahun melalui edutainment dengan metode sains sederhana efektiv diterapkan dalam pembelajaran di TK khususnya dikelompok A atau pada usia $4-5$ tahun.

\section{DAFTAR PUSTAKA}

Sugiyono. (2017). Metode Penelitian Kuantitatif, Kualitatif, dan $R \& D$. Bandung: Alfabeta.

Yusuf, A. M. (2016). Metode penelitian kuantitatif, kualitatif \& penelitian gabungan. Prenada Media.

Suyadi. (2015). Teori pembelajaran anak didik dibawah usia 8 tahun dalam kajian neurosains. Remaja rosdakarya.

Putra, S. R. (2013). Desain Belajar Mengajar Kreatif Berbasis Sains. Yogyakarta: DIVA Press.

Raharjo. Sahid. Error! Hyperlink reference not valid. diakses tanggal 07 Juli 19 jam 21:47

Sholeh, H.M (2011). Metode Edutainment. Yogyakarta: DIVA Press. 


\section{JURNAL GERIA}

ISSN : 2614-6347 (Print) 2714-4107 (Online)

Vol.2 | No.5 | September 2019

Sajidha Hannah (2016) http://hannaexpoest.blogspot.com/2016/01/ma kalah-masalah-pendidikan-di indonesia. html diakses tanggal 2 agustus 2019

Melani Novi, (2014) Error! Hyperlink reference not valid. diakses tanggal 25 juli 2019.

Yusuf Randa, (2015) https://randayusuf.blogspot.com/2 $\underline{015 / 05 / \text { knowledge-management- }}$ peng ertian -dan.html diakses tanggal 2 agustus 2019.

Afida Riani Hidayat, 135040120 (2017)

Prior Knowledge Dan Self

Efficacy Siswa Sma Pasundan 3 Bandung Pada Pembelajaran Sistem Reproduksi. Skripsi(S1) Thesis, Fkip Unpas.

Sumayana, Yena (2013) Efektivitas Metode Mind Mapping Dalam Peningkatan Kemampuan Menulis Laporan Pengamatan Dan Kemampuan Berpikir Kritis Siswa Pada Mata Pelajaran Bahasa Indonesia. S2 Thesis, Universitas Pendidikan Indonesia. 